\title{
Implementation Status of Nursing Process and Associated Factors AmongNurses Working in Tikur Anbessa Specialized Hospital Addis Ababa, Ethiopia, 2017
}

\author{
Tsiyon Birhanu Wube', Teshome Habte Wurjine ${ }^{2, ~ *, ~ Y o h a n n e s ~ A y a l e w ~ B e k e l e ~}{ }^{2}$ \\ ${ }^{1}$ Department of Nursing, College of Health Sciences, Aksum University, Tigray, Ethiopia \\ ${ }^{2}$ Department of Nursing, College of Health Sciences, Addis Ababa University, Addis Ababa, Ethiopia
}

Email address:

tsyontd@gmail.com (T. B. Wube), teshome.habte@aau.edu.et (T. H. Wurjine), yohannes.ayalew@aau.edu.et (Y. A. Bekele)

${ }^{*}$ Corresponding author

\section{To cite this article:}

Tsiyon Birhanu Wube, Teshome Habte Wurjine, Yohannes Ayalew Bekele. Implementation Status of Nursing Process and Associated Factors AmongNurses Working in Tikur Anbessa Specialized Hospital Addis Ababa, Ethiopia, 2017. American Journal of Nursing Science. Vol. 8, No. 3, 2019, pp. 81-91. doi: 10.11648/j.ajns.20190803.11

Received: January 29, 2019; Accepted: March 8, 2019; Published: April 1, 2019

\begin{abstract}
Background: -Nursing process is a systematic method of assessing, diagnosing, planning, intervening and evaluating individualized care for clients in any state of health. Even if, its implementation is mandatory due to many factors, it is poorly implemented in most of the health institutions in the country and resulted loss of quality nursing care. Objective:-The aim of this study was to assess the implementation status of nursing process and its' associated factors among nurses in Tikur Anbessa Specialized Hospitals. Method: -A cross-sectional study design was conducted from February to March 2017 with a total of 151 participants and 271 medical records were selected by using Simple random sampling method. The collected datachecked for accuracy, completeness and entered into epi- data version 3.1 and analyzed using SPSS version 22. Bivariate and multivariate logistic regressions were used to identify associated factors with nursing process implementation. Statistical significance interpreted using odds ratio with $95 \%$ CI \& P value $<0.05$. Result: - A total of 151 respondents, mean age was 28.5 years and about $86(57.6 \%)$ had implement nursing process. Working in medical ward unit [AOR=3.43, $(1.01,11.5)$, surgical unit $[\mathrm{AOR}=9.59(2.21,41.61)$, organized environment $[\mathrm{AOR}=4.44(1.80,10.95)$ and Good Knowledge $[\mathrm{AOR}=10.2,(3.05$, 34.1 ) were significantly associated with the implementation of 271 medical card review 239 of the cards included nursing process registration form, amongthose $65(24.6 \%)$ of them was found to include the nursing process and those staying in the hospital for $11-20$ days and $21-30$ days was $[\mathrm{AOR}=1.8895(1.01,3.53)$ and $\mathrm{AOR}=2.84(1.06,7.5)$ were significantly associated with implementation of the nursing process. Conclusion and recommendation: In this studythe level of nursing Process implementation was suboptimal and it needs further intervention to increase its utilization. Those who had worked at medical and surgical unit, organized work environment, good knowledge and length of stay were identified as possible determinant factors for the implementation of nursing process. Health care authorities must help in promotion of the health care with employing sufficient nurses, educational training and providing necessary situations for nursing process.
\end{abstract}

Keywords: Nursing Process, Determinants of Nursing Process, Nurses

\section{Introduction}

\subsection{Background}

Nursing is a profession that ensures the successful implementation of interventions which welcome and nurture life, promotes or restores health, enables the means to a peaceful, dignified and pain-free death [1]. It demands a consistent, high level of critical thought, coupled with critical actions. This criticality is equated with the nursing process, which confines to a dynamic, single right solution, problemsolving process [2].

One of the most important policies in nursing job is using the nursing process model which is the systematic framework to assess the patients' needs in order to make clinical decisions based on complete science and art [3]. It was 
developed based on the assumption that professional nursing practice is interpersonal in nature, assumes human beings as holistic, thereby acknowledging mind, body, emotion, spirit and environment are not separated but function as a whole [1].

The Nursing Process is a systematic problem-solving approach used to identify, prevent and treat actual or potential health problems and promote wellness. This includes five major steps, namely; Assessment, Nursing diagnosis, planning, implementation, and evaluating [4].

Assessment involves gathering subjective and objective data about the client's condition, diagnosis encompasses the human response needs that nurses deal with, planning involves prioritizing problem, setting goal and expected outcome, implementation plans, implementation of care involves skillful and competent actions taken to meet the needs of the client, evaluation is done to determine the success of the implemented care [5].

Importance of nursing process in the health care system is to: Speed up diagnosis and treatment of actual and potential health problems, reduce the incidence of hospital stays, improve communication through documentation, prevent errors, omissions, and unnecessary repetitions, Promotes flexibility and independent thinking, Tailors interventions for the individual (not just the disease) and Helps nurses to gain the satisfaction of getting results [1].

In theory, the majority of nurses have knowledge of the nursing process, but they do not apply it in practice due to many factors. As a result, problems identified with regard to the nursing practice, including a loss of quality care, disorganization of the service, and conflicting role among nurses, dissatisfaction of customers with the care provided, medication error, poor disease prognosis, and increased mortality. These problems are manageable if a nurse can properly implement the nursing process [6].

\subsection{Statement of the Problem}

Nursing process is a global concept, which forms the foundation of nursing as a profession. The use of nursing process in most hospitals is lagging behind due to different factors despite all the effort of nursing professionals to implement its use [7].

Different world health care organizations like world health organization (WHO), InternationalCouncil of Nursing and the American Joint Commission on Accreditation of Hospital NursingService Standards highly recommended and gave emphasis that nursing process should be usedin nursing documentation and promoted with the use of every nursing care [8]. According to the standards of nursing actions in the United States and Canada, performing professional nursing cares demand using the nursing process and, thus, participation of nurses in activities that lead to increase in knowledge toward nursing process is strongly recommended [9]. However, many evidences have shown that in most cases, the nursing process is carrying out by routine caring performance form rather than the systematic one $[10,11]$. Despite the introduction of nursing process in the school of nursing and department of nursing long ago, but the impact is not felt in the clinical area in certain parts of Africa like Ethiopia.

The utilization of the nursing process in a part of Africa has not reached the standard that is set by the profession's regulatory body. Factors influence its utilization in Africa need to be understood by comparing to, those factors that influence utilization of the nursing process in other parts of the world [12]. If the nursing process is not valued and not used, then nurses might continue to intervene in standardized nursing procedures on the basis of medical diagnoses rather than a rational based on the steps of the nursing process, then the question might arise in what way nurses assume accountability and responsibility for the patient and how the quality of nursing care could be measured [13]. As a result of poor implementation of the nursing process, reduction of job satisfaction and quality of care, devaluation of this profession by nurses themselves and their excessive dependency to the physicians, incorrect evaluation, neglecting of some of the authorities in this field, indisputable obedience, doing routine activities without thinking, conducting one dimensional care, reduce in patient's independence and costing heavy expenses due to doing repeated acts will happen [14].

The implementation of nursing process by nursing practitioners in different health care settingin Ethiopia is still not well developed and organized [15, 16]. Currently the Ethiopian health care system, demand the application of nursing process in every clinical practice. Due to this Ethiopian Federal Ministry of Health prepare and distribute standardized nursing care plan and nursing care practice standards for all health care settings and fostered increased awareness in use of nursing process through training in collaboration with different NGOs like Clinton foundation, ICAP -Ethiopia, and I-tech Ethiopia throughout the country. Despite this the utilization of nursing process in health institutions in Ethiopia there is still a big gap on the implementation of nursing process among nurses working in hospitals [1]. For example, of the total of 358 Medical records reviews in a governmental hospital of Harare and Dire Dawa in 2015, the nursing process registration form included in 134 cards among those only $26 \%$ was included five steps of nursing process [17]. Also, a study conducted in Addis Ababa selected governmental hospitals among 192 participated nurses, $52.1 \%$ of them implement while $47.9 \%$ of them did not implement the nursing process [18]. Similarly, a study carried out on nurses working in selected government hospitals in southwest Ethiopia, show that from 138 participant $73.9 \%$ of the nurses applies the nursing process [19]. In contrast to this, study conducted in Mekelle zone hospitals northern Ethiopia, all the 200 respondents did not apply any of the nursing process steps [15]. Hence, all the studies conducted in Ethiopia except the study conducted in a governmental hospital ofHareri and Dire Dawa did not try to cross check the response of nurses with the actual medical card records done towards the implementation of nursing process. This is important to obtain the exact result how the utilization practice looks like by avoiding social desirability 
bias. In this study both the medical record review and response of nurse participants included which was not done by other researches.

Even though the Federal government of Ethiopia gives more emphasis on quality of health service in general and quality of nursing care in particular [1], there is still a big problem on the utilization of nursing process among nurses working in hospitals. [15] With this view, this study intended to be conducted to explore more about the factors that contribute to implementation nursing process in a well coherent manner and to forward a possible solution for the improvement of quality nursing care.

\subsection{Significance of the Study}

Poor quality of implementing nursing care plan leads to poor delivery of nursing care topatients. Quality of nursing care can be improved, if the factors hindering the application ofnursing care plan are investigated.

This study assesses the barriers encountered by nurses in their daily implementation of nursingprocess which is a framework of delivering quality nursing care; this eventually serves as areference on the challenges encountered by nurses and how best they can be solved. Therefore a better understanding of factors affecting the implementation of nursing process canmake nursing directors and decision makers aware of the factors and design a strategy in educational programs, governmental intervention and policy modification to tackle thesefactors. It will also recommend possible solutions for concerned bodies and used as baselineinformation for further study. Moreover, it helps the respondents in reminding and testing their knowledge and practice ofnursing process implementation. Since, the study has included medical record review, it willexamine the way how nurses implement components of the nursing process in the hospital.

\subsection{Conceptual Frame Work}

The conceptual frame work was adapted and modified from reviewing of many previous studies conducted [17, 19, and 20]. According to the frame work factors like sociodemographic of nurses (age, sex, educational level, year of service, position of nurses), knowledge and attitude of nurses, patient related factors (Cooperativeness, Length of stay) and organizational factors those may be either facilitator or barrier factors directly affect the implementation level of nursing process.

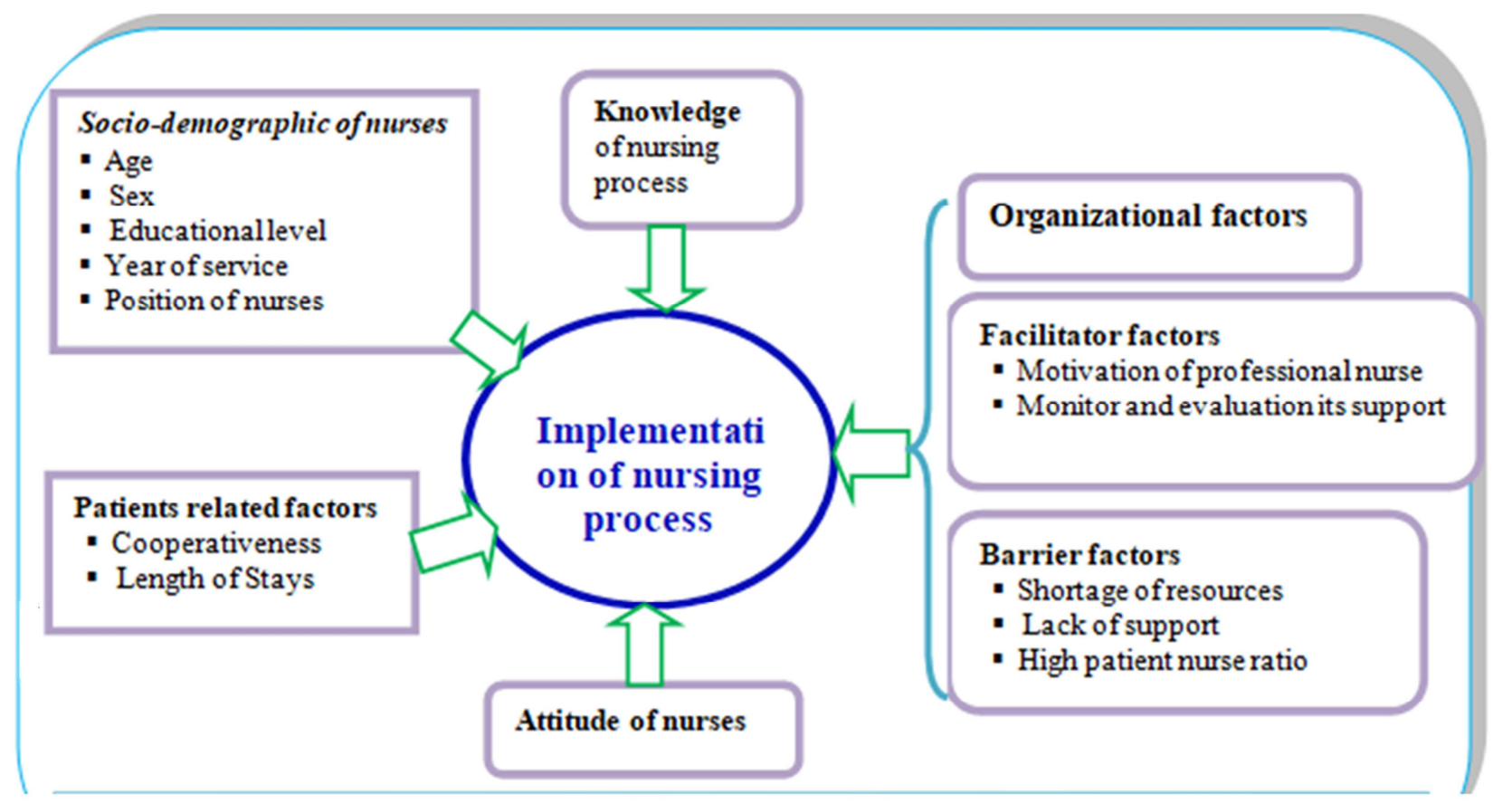

Figure 1. Conceptual frame work on nursing process implementation and associated factors.

\section{Methods and Materials}

\subsection{Study Setting and Design}

\subsubsection{Study Setting}

The study was conducted in Addis Ababa, the capital city of Ethiopia which was founded in 1886by Emperor Menelik II and seat of Africa Union. It is the largest city of the country and occupies an estimated area of526.99 square kilometers. Based on figures from the Central Statistical
Agency of Ethiopia, Addis Ababa has an estimated total population of $3,384,569$ (CSA 2007). From the total 30 Hospitals in the city 12 found to be owned by the government. Among those, TikurAnbessaSpecialized Hospital (TASH) is one of them. According to data from the hospital's administrative unit; the hospital was inaugurated in 1964 E. C. This hospital sees approximately 370,000 400,000 patients per year and it have 625 beds and 836 nursing staffs. it is a specializedreferral teaching hospital which is managed by Addis Ababa University (AAU). 


\subsubsection{Study Design and Period}

A cross-sectional study conducted using quantitative methods from March, 2017 - April 2017.

\subsection{Study Population, Sample Size Determination and Sampling Procedure}

\subsubsection{Study Population}

All nurses working in the ward (in-patient department) in TikurAnbessa Specialized Hospital. A one month medical record which is from March 1, 2017toApril 1, 2017 was taken as studyUnit: this helped to obtain recent data on the practice nursing process.

\subsubsection{Sample Size Determination}

For nurses' participants: The sample size was determined by using single population proportion formula with marginal error (d) that will tolerate in either sides of the true proportionto be $5 \%$, and using $95 \%$ confidence level, $\alpha=0.05$ and adding $10 \%$ to compensate for nonresponses and the proportion of application of Nursing Process was (P), 0.36 from the previous research [19].

$$
\begin{gathered}
\mathrm{n}=\frac{\left(Z_{\alpha / 2}\right)^{2} \mathrm{P}(1-\mathrm{P})}{\mathrm{d}^{2}} \\
\mathrm{n}=\frac{(1.96)^{2}(0.36)(1-0.36)}{(0.005)^{2}} \\
\mathrm{n}=354
\end{gathered}
$$

Where;

$\mathrm{n}=$ minimum sample size required for the study

$\mathrm{Z} \alpha / 2=$ standard normal distribution $(=1.96)$ with confidence interval of $95 \%$ and $\alpha=0.05$

$\mathrm{p}=$ prevalence Proportion of nursing process implementation from previous study $(\mathrm{p}=0.36)$

Since the total nurses found in the selected inpatient departments in (222) was less-than final sample size which was (354) and the source population was $<10,000$, thefinite population correction formula was employed and the final sample was 137.

By assuming non-response rate $10 \%$ the final sample size will be $=151$.

For the medical record review; The sample size was determined by using single population

Proportion formula with $\mathrm{P}=0.5$

$$
\begin{gathered}
\mathrm{n}=\frac{\left(\mathrm{Z}_{\alpha / 2}\right)^{2} \mathrm{P}(1-\mathrm{P})}{\mathrm{d}^{2}} \\
\mathrm{n}=\frac{(1.96)^{2}(0.5)(1-0.5)}{(0.005)^{2}} \\
\mathrm{n}=384
\end{gathered}
$$

The total number of cards registered admitted and discharged within one month was 675. Byusing the correction formula and addition of $10 \%$ non response rate the final sample sizebecome 271.

\subsubsection{Sampling Procedure}

From the total nurses in the hospital first, nurses working in In-patient department were selectedthen, among them nurses working in emergency, labor and delivery, Intensive Care Unit, Neonatal Intensive Care Unit and operation theaters were excluded. From the selected nurses byusing the sampling frame which was obtained from the director office, nurses selected withsimple random sampling method after proportional allocation for each unit.

Similar to the nurse's participant's medical cards selected with the same procedure. The medicalcard number obtained from HMIS registration book by taking the admission and dischargedrecord of one month which is from March 01 to April 01, 2017.

\subsection{Study Variables}

1. Dependent (outcome) variable: Implementation of nursing process

2. Independent variable: Socio-demographic characteristics:- sex, age, educational status, working unit, working position and work experience.

Organizational factors:- on job training, adequate staffing, resource, supportiveadministration, time, monitoring and evaluation, work load and condition of workingenvironment.

Nurse related factors:- knowledge and attitude

Patient related factors:-cooperativeness and length of stay

\subsection{Eligibility Criteria}

Inclusion criteria

1. Nurses working in TASH for equal or greater than six months.

2. Nurses who are working in In-patient wards include medical, surgical, obstetrics and gynecology, oncology, pediatric and orthopedic ward.

Exclusion criteria

1. Nurses working in the outpatient department.

2. Nurses working in emergency unit, labor and delivery unit, Intensive Care Unit, Neonatal Intensive Care Unit and operation theaters because these units has their own registration sheet other than nursing process steps.

3. Medical Card Numbers registered in oncology ward. In this ward there are a lot ofpatients admitted per week but, most of them are an admission for the purpose of routinetreatment and radiology check up.

4. Number Patients admitted as a result of illness is lessso there may be the chance of getting false result.

\subsection{Operational Definitions}

This study tries to operationalized terms by taking the previous studies as a base line $[16,17,19,20]$.

\subsubsection{Operational Definition for Questionnaires}

Implementation of nursing process: the status of nursing process application in practice bynurses in the hospitals.

1. Implemented- is the level of nursing process 
application in which the nurses renderednursing care based on all steps of the nursing process and did documentation in thepatient's record.

2. Not implemented-nursing care is not carried out based on all steps of the nursingprocess and not documented.

3. Nurses' Knowledge -level of nurse's awareness about nursing process and classified as:

4. Good knowledge: for nurses those who answer greater or equal to $80 \%$ of theknowledge related questions.

5. Fair knowledge: for nurses those who answer 60 to $79 \%$ of the knowledge relatedquestions.

6. Poor knowledge: for nurses those who answer less than $60 \%$ of the knowledge relatedquestions.

7. Nurses' Attitude - means the nurses perception towards nursing process and classified as:

8. Favorable attitude: for those who have a mean score of more than or equal to $50 \%$ ofattitude related questions.

9. Unfavorable attitude: for those who have mean score of less than $50 \%$ of attituderelated questions.

\subsubsection{Operational Definition for Medical Card Review}

i) Nursing process implementation

(a) Implemented -cards those includes nursing charts as well as contain all steps ofnursing process correctly.

(b) Not implemented -cards those not include nursing charts and did not complete allthe steps of the nursing process in a correct way.

ii) Performance of the steps of nursing process

(a) Fully performed -cards contain all the required statements or action which assignsfor those steps.

(b) Partially performed -cards contain some of the expected statements or actionsassigned for that step but not fully performed.

(c) Incorrectly performed -cards which contain statements or actions which areincorrect or inappropriate for the given steps

(d) not performed - cards which did not had any documented statements or actions forthe given steps.

\subsection{Data Collection Instrument}

For nurse participants self administered structured questionnaire used. The questioner isadopted and modified from relevant review of many literatures [16, 17, 18, and 19]. Thequestionnaire composed of four parts: (1): include the socio-demographic data of the studyparticipant's such as age, sex, educational qualification, years in service and work unit. (2)Implementation related questions, organizational and nurses -related questions. (3)Knowledge related question, (4) attitude -related questions based on Likert Scales. For medical record review the check list and measuring criteria was prepared based onprevious studies, text books, NANDA check list, Gordon's Functional Health Pattern anassessment tool and nursing care practices standards, Reference manual for nurses in Ethiopia [1, 17, 21].

\subsection{Data Collection and Quality Control}

To ensure quality of data training given for data collectors and supervisor for two days prior tostudy period on objectives of the study, how to collect data, regarding ethical issues, and ondata quality. Before the actual data collection to determine the questioner appropriateness andethical soundness it was pretested on $10 \%$ of sample size in zewiditu Memorial Hospital. Thefinding of the pretest incorporated to modify and clarify the collection tool before actual datacollection one supervisors who closely follow the data collection process and four datacollectors recruited among the BSC nurses and three card collectors were also assigned formedical card review. During data collection, the supervisor had routine checkups for itscompleteness and scientific soundness. Additionally, the principal investigator checked thefilled questionnaire and gave feedback for supervisor daily.

\subsection{Data Processing and Analysis}

Data first cleared, coded and entered into computer using Epi-data version 3.1 and errorsrelated to inconsistency of data checked and corrected during data cleaning. Then data enteredto SPSS version 22 statistical software packages. Descriptive statistics such as percentagefrequency distribution, mean, ratio and standard deviation of different characteristics analyzed. Bi-variate analysis used to explore association between dependent and independent variable.

\subsection{Ethical Consideration}

Ethical clearance was obtained from the Institutional Review Board of Addis Ababa University, College of Health Sciences, Department of Nursing and Midwifery, fromwhich an official letter written to Tikur Anbessa Specialized Hospital to got their permissionand cooperation for the study. Approvals obtained from the mentioned hospital. In addition, consent obtained from participant, and confidentiality kept also, the respondents had the rightnot to participate or withdraw from the study at any stage of the study.

\subsection{Dissemination and Utilization of the Result}

The result of this research submitted to the ministry of Health and Addis Ababa University College of health science, school of nursing and midwifery. The result also communicated to Tikur Anbessa Specialized Hospital was the research study was conducted.

\section{Result}

Total of 151 study participants were interviewed using semi- structured questionnaire and 271one month admitted and discharged medical card was reviewed with response rate of $95 \%$.

\subsection{Socio Demographic Status of Nurses}

From the total 151 Respondents 99(65.6\%) were females. Majority of the study participants $118(78.1 \%)$ were in the age group of 25 to 44years. Mean age of the respondents were 28.5 years with minimum age of 21 and maximum age 
of 55. As depicted in Table 1 below, Work experience of nurse varies from one to thirty years while majority lies on less or equal to four years (mean 4.92). Nurses whose clinical service was less than and equal to four years were $91(60.3 \%)$ and the rest $61(39.7 \%)$ nurses had greater than four years.

Table 1. Socio demographic characteristics of nurses in relation to the implementation of nursing process in TASH hospital Addis Ababa Ethiopia, in 2017G. C.

\begin{tabular}{|c|c|c|c|c|}
\hline Variable & Category & Not implementedN (\%) & ImplementedN (\%) & TotalN (\%) \\
\hline \multirow{2}{*}{ Sex } & Male & $26(40.6$ & $20(29.6)$ & $52(34.4)$ \\
\hline & Female & $38(59.4$ & $61(70.1)$ & $99(65.6)$ \\
\hline \multirow{4}{*}{ Age } & $\leq 24$ & $12(18.8)$ & $17(19.5)$ & $29(19.2)$ \\
\hline & $25-44$ & $51(79.7)$ & $67(77)$ & $118(78.1)$ \\
\hline & $45-54$ & $1(1.6)$ & $2(2.3)$ & $3(2)$ \\
\hline & $\geq 55$ & $0(0.0)$ & $1(1.1)$ & $1(0.7)$ \\
\hline \multirow{2}{*}{ Educational } & Degree & $54(84.4$ & $84(96.9)$ & $138(91.4)$ \\
\hline & Master & $10(15.6)$ & $3(3.4)$ & $13(8.6)$ \\
\hline \multirow{5}{*}{ Working unit } & Medical Ward & $15(23.4)$ & $27(31)$ & $42(27.8)$ \\
\hline & Surgical Ward & $9(14.1)$ & $27(31)$ & $36(23.8)$ \\
\hline & Pediatric Ward & $19(29.7)$ & $11(12.6)$ & $30(19.9)$ \\
\hline & Gyn/Obs ward & $8(12.5)$ & $10(11.5)$ & 18(11.9) \\
\hline & Orthopedic andOncology & $13(20.3)$ & $12(13.8)$ & $25(16.6)$ \\
\hline \multirow{3}{*}{$\begin{array}{l}\text { Working } \\
\text { position }\end{array}$} & Head nurse & $5(3.3)$ & $9(6)$ & $14(9.3)$ \\
\hline & Case team coordinator & $7(4.6)$ & $5(3.3)$ & $12(7.9)$ \\
\hline & Staff nurse & $52(34.4)$ & $73(48.3)$ & $125(82.8)$ \\
\hline \multirow{5}{*}{ Service } & $\leq 4$ & $33(21.9)$ & $58(38.4)$ & $91(60.3)$ \\
\hline & $5-10 \mathrm{yrs}$ & $27(17.9)$ & $23(15.2)$ & $50(33.1)$ \\
\hline & $11-15 y r s$ & $2(1.3)$ & $5(3.3)$ & $7(4.6)$ \\
\hline & $16-20$ & $1(0.7)$ & 0 & $1(0.7)$ \\
\hline & $\geq 21$ & $1(0.7)$ & $1(0.7)$ & $2(1.3)$ \\
\hline
\end{tabular}

\subsection{Nursing Process Implementation Status}

From the total of 151 respondents, 65(42.4\%) did not document and implement all the fivesteps of nursing process whereas $86(57.6 \%)$ of the respondents mentioned that they did nursingcare based on nursing process as shown in Figure 2 below using all five steps: assessment, nursing diagnosis, planning, implementation and evaluation and done documentation.

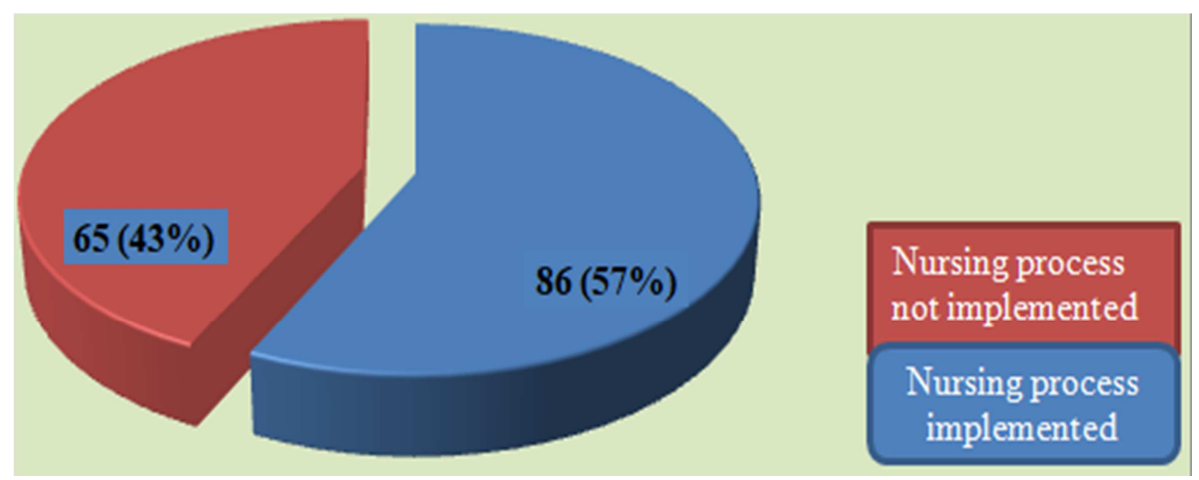

Figure 2. Nursing process implementation status at TikurAnbesa Specialized Hospital, Addis Ababa, Ethiopia.

From $47(31 \%)$ participants respond on the influencing factors for not implementing nursingprocess rated according to reason listed here; there are lots of patients so there is no enough timeto apply17 (36.2\%), it is not as such important 11 (23.4\%), lack of enough resource 9 (19.1\%), itis not practically applicable $5(10.6 \%)$, Patients are un cooperative or discharged beforecompleting the planned $5(10.6 \%)$.

Additionally, a total 271 medical records of admitted patients were reviewed to evaluate documentation on the nursing process. The result showed that 239 (88.2\%) of the cards include the form or chart necessary to register the phases of the nursing process documentation, but among them only $65(24 \%)$ were recorded all the five steps of the nursing process. Among the steps of the nursing process measuring evaluation $210(77.8 \%)$ is not performed. In contrast $213(78.6 \%)$ of the evaluation part stated without measurement or quantification of their outcome (in most of the cards on evaluation part they state; the patient has a good prognosis instead of measuring by how much the improvement is achieved. From the assessment by using Gordon's Functional Health Pattern as an assessment tool, objective data are less performed than the subjective data. 
Nursing diagnosis was recorded correctly using NANDA label with three part statement etiology, related factors and defining characteristics were $165(60.9 \%), 155(57.2 \%)$ and $162(59.8 \%)$ respectively.

\subsection{Knowledge and Attitude of Nurses on Nursing Process}

There were ten questions about knowledge which were measured as good knowledge, fair knowledge and poor knowledge. Majority of the participants $63(41.7 \%$ ) had poor knowledgewhich is followed by 50(33.1\%) fair knowledge. Regarding the overall attitude of nurses towards nursing process, among nine attitudes relatedquestions, 64(42.4\%) answer the attitude question above the mean and the remaining $87(57.6 \%)$ had unfavorable attitude towards the nursing process.

According to the medical card review, Even though majority of the cards document nursingdiagnosis correctly, their stated component was very limited to some statements or actions thisraveled that majority of nurses has no enough knowledge on nursing diagnosis.

\subsection{Organizational Related Factors}

Regarding the organizational factors $91(60.3 \%)$ said that the hospital administration were supportive in the application of nursing process and $124(82.1 \%)$ mentioned there is a regularmonitoring and evaluation has done. There are also participants, which forward complain likeinadequate resource $87(57.6 \%)$, in-optimal nurse to patient ratio 93 (61.6\%), rules made withoutconsidering staffs $77(51 \%)$ and presence of unorganized work environment $89(58.6 \%)$ as show in Table 2 below.

Most of the respondents137 (90.7\%) stated they work more than 8 hours per a day and servegreater than 6 patients per a day112 (74.2\%).

Table 2. Organizational factors in relation to the implementation status of nursing processamong nurses working in TASH, Addis Ababa, Ethiopia, 2017 G. C.

\begin{tabular}{|c|c|c|c|c|}
\hline Variable & Category & Not implement N (\%) & Implement N (\%) & Total \\
\hline \multirow{2}{*}{ Working hour } & $\leq 8 \mathrm{hrs}$ & $7(10.9)$ & $7(8)$ & $14(9.3)$ \\
\hline & $>8 \mathrm{hrs}$ & $57(89.3)$ & $80(92)$ & $137(90.7)$ \\
\hline \multirow{2}{*}{ Optimal nurse to patient ratio } & Yes & $19(29.7)$ & $39(44.8)$ & $58(38.4)$ \\
\hline & No & $45(70.3)$ & $48(55.2)$ & $93(61.6)$ \\
\hline \multirow{2}{*}{ Working environment } & Organized & $18(28.1)$ & $44(50.6)$ & $62(41.1)$ \\
\hline & Disorganized & $46(71.9)$ & $43(49.4)$ & $89(58.9)$ \\
\hline \multirow{2}{*}{ Service patients per Day } & $\leq 6$ & $15(23.4)$ & $24(27.6)$ & $39(25.8)$ \\
\hline & $>6$ & $49(76.6)$ & $63(72.4)$ & $112(74.2)$ \\
\hline \multirow{3}{*}{ Work place anxiety } & Caring manyPatients & $21(32.8)$ & $37(42.5)$ & $58(38.4)$ \\
\hline & Rule withoutconsidering staff & $34(53.1)$ & $43(49.4)$ & $77(51)$ \\
\hline & Harassing co-workers & $9(14.1)$ & $7(8)$ & $12(10.5)$ \\
\hline \multirow{2}{*}{ Resource } & Yes & $25(39.1)$ & $39(44.8)$ & $64(42.8)$ \\
\hline & No & $39(60.9)$ & $48(55.2)$ & $87(57.6)$ \\
\hline Support & No & $31(48.4)$ & $29(33.3)$ & $60(39.7)$ \\
\hline \multirow{2}{*}{ Monitor } & Yes & $49(76.6)$ & $75(86.2)$ & $124(82.1)$ \\
\hline & No & $15(23.4)$ & $12(13.8)$ & $27(17.9)$ \\
\hline \multirow{2}{*}{ Feed back } & Yes & $11(17.2)$ & $25(28.7)$ & $36(23.8)$ \\
\hline & No & $53(82.8)$ & $62(71.3)$ & $115(76.2)$ \\
\hline
\end{tabular}

\subsection{Factors Associated with Implementation of Nursing Process}

As can be noted from the result of bivariate analysis (Table 3 and 4), eleven of the sixteen variables show a significant association with the implementation of the nursing process at the $5 \%$ level ofsignificance. Multivariable logistic regression was done by taking 11 variables into account simultaneously. The backward method, regression was used. The majority of variables which showed significantassociated with implementation of nursing process in bivariate analysis could not persist assignificant in the multivariable analysis. These covariates Were; sex, educational level, organizational status, nurse to patient ratio, anxiety, administration support, administration monitor, feedback from administration, and attitude to nursing process.

In the multivariate binary logistic regression analysis, only three variables had shown an overallsignificant effect on the implementation of the nursing process at the $5 \%$ level of significanceWorking in the medical ward and surgical ward unit shows a significant association with theimplementation of the nursing process. The odds of working in the medical ward unit were 3 times more associated with implementation of nursing process than to those who were working in the oncology and orthopedic unit $[\mathrm{AOR}=3.43$ at $95 \% \mathrm{CI}(1.01$, 11.5), and the odds of the surgical ward unit were 9 times more likely associated with implementation of nursing process $[\mathrm{AOR}=9.59$ at $95 \% \mathrm{CI}(2.21,41.6)$.

Those nurses who were working in organized environment were significantly associated withimplementation of nursing process than to their counterpart. The odds of working in organizedenvironment were 4 times more likely associated with the outcome variable of implementation ofnursing process $[\mathrm{AOR}=4.44$ at $95 \% \mathrm{CI}(1.80,10.95)$. 
Those who had good knowledge had significant association with the outcome variable ofimplementation of the nursing process. The odds of good knowledge were 10 more likely toimplement nursing process than those had poor knowledge $[\mathrm{AOR}=10.2$ at $95 \% \mathrm{CI}(3.05,34.1)$.

Table 3. Bivariate and multivariate analysis of implementation of nursing process among nursesworking in TASH, Addis Ababa, Ethiopia, 2017 G. C.

\begin{tabular}{|c|c|c|c|c|c|}
\hline Variable & Category & Not implement $\mathbf{N}(\%)$ & ImplementN (\%) & COR & AOR \\
\hline \multirow{2}{*}{ Sex } & Male & $26(40.6)$ & $20(29.6)$ & $0.6(0.3,1,23)$ & $0.6(0.32,1.23)$ \\
\hline & Female & $38(59.4)$ & $61(70.1)$ & 1 & 1 \\
\hline \multirow{4}{*}{ Working unit } & Medical & $15(23.4)$ & $27(31)$ & $1.95(0.71,5.33)$ & $3.43(1.01,11.5)^{* *}$ \\
\hline & Surgical & $9(14.1)$ & $27(31)$ & $3.25(1.09,9.65)$ & $9.59(2.21,41.61)^{* *}$ \\
\hline & Pediatric & $19(29.7)$ & $11(12.6)$ & $0.62(0.21,1.84)$ & $1.88(0.32,4.36)$ \\
\hline & GYN/OBS & $8(12.5)$ & $10(11.5)$ & $1.35(0.40,4.75)$ & $2.27(0.52,9.86)$ \\
\hline \multirow{2}{*}{ Nurse to patient ratio } & Yes & $19(29.7)$ & $39(44.8)$ & $1.924(0.97,3.8)$ & $1.7(0.69,4.59)$ \\
\hline & No & $45(70.3)$ & $48(55.2)$ & 1 & 1 \\
\hline \multirow{2}{*}{ Working Environment } & Organized & $18(28.1)$ & $44(50.6)$ & $2.62(1.3,5.2)$ & $4.44(1.8,10.95)^{* *}$ \\
\hline & Disorganized & $46(71.9)$ & $43(49.4)$ & 1 & 1 \\
\hline \multirow[b]{2}{*}{ Anxiety } & Caring many patients & $21(32.8)$ & $37(42.5)$ & 1 & 1 \\
\hline & Rule without considering staff & $34(53.1)$ & $43(49.4)$ & $0.58(0.57,6.01)$ & $3.561(0.25,50.6)$ \\
\hline \multirow{2}{*}{ Support } & Yes & $33(51.6)$ & $58(66.7)$ & $1.879(0.97,3.6)$ & $0.7(0.27,1.93)$ \\
\hline & No & $31(48.4)$ & $29(33.3)$ & 1 & 1 \\
\hline \multirow{2}{*}{ Monitor } & Yes & $49(76.6)$ & $75(86.2)$ & $1.9(0.874,4.32)$ & $1.46(0.47,4.5)$ \\
\hline & No & $15(23.4)$ & $12(13.8)$ & 1 & 1 \\
\hline \multirow{2}{*}{ Feed back } & Yes & $15(23.4)$ & $12(13.8)$ & 1 & 1 \\
\hline & No & $53(82.8)$ & $62(71.3)$ & 1 & 1 \\
\hline \multirow{3}{*}{ Knowledge } & Poor & $53(82.8)$ & $62(71.3)$ & 1 & 1 \\
\hline & Fair & 21(13.9) & $29(19.2)$ & $1.8(0.86,3.90)$ & $1.71(0.70,4.15)$ \\
\hline & Good & $7(4.6)$ & $31(20.5)$ & $5.9(2.2,15.4)$ & $10.2(3.05,34.1)^{* *}$ \\
\hline \multirow{2}{*}{ Attitude } & Favorable & $33(21.9)$ & $31(20.5)$ & 0.6 & $9(0.29,1.6)$ \\
\hline & Unfavorable & $31(20.5)$ & $56(37.1)$ & 1 & 1 \\
\hline
\end{tabular}

** Significant at $\mathrm{p}$ value 0.05

As can be noted from the result of bi-variate analysis in the Table 4 below, two of the four variables show asignificant association with the implementation of the nursing process from medical card review at the $5 \%$ level of significance. Of these lengths of stay and having chart for documentation, were entered in multivariate logistic regression with significance level at 0.2 . Multivariable logistic regression was done by taking two variables into account simultaneously. The backward method, regression was used.

Table 4. Bivariate and multivariate analysis of implementation of nursing process among nurses working in TASH, Addis Ababa, Ethiopia, 2017 G. C.

\begin{tabular}{|c|c|c|c|c|c|}
\hline Variable & Category & Notimplement & Implement & COR & AOR \\
\hline \multirow{4}{*}{ Length of stay in days } & $\leq 10$ & $132(48.7)$ & $31(11.4)$ & 1 & 1 \\
\hline & $11-20$ & $52(19.2)$ & $23(8.5)$ & $1.8(1.01,3.5)$ & $1.88(1.01,3.53)^{*}$ \\
\hline & $31-40$ & $4(1.5)$ & $6(2.2)$ & $6.4(1.69,24.0$ & $6.4(1.69,24)$ \\
\hline & $\geq 41$ & $3(1.1)$ & $0(0.0)$ & $0.0(0.00)$ & $0.9(0.0,0.0)$ \\
\hline \multirow{2}{*}{ Having chartfor documentation } & Yes & $174(64.2)$ & $65(24)$ & $0.27(0.08,0.94)$ & $0.4(0.11,1.36)$ \\
\hline & NO & $29(10.7)$ & $3(1.1)$ & 1 & 1 \\
\hline
\end{tabular}

In the multivariate binary logistic regression analysis, only one variable hadshown an overall significant effect on the implementation of the nursing process at the $5 \%$ level of significance. Those patients staying at the hospital for 11-20 days and 21-30 days were significantly associated with the outcome variable. Those stay in the hospital for 11-20 days and 21-30 days was $1.88(1.01,3.53)$ and $2.84(1.1,7.5)$ times more likely associated with implementation of nursing process than staying less than ten days respectively.

\section{Discussion}

The aim of this study was to assess the implementation status of nursing process and associatedfactors among nurses working in Tikur Anbessa Specialized Hospital, Addis Ababa, Ethiopia 2017. 


\subsection{Nursing Process Implementation Status}

The level of implementation of nursing process was $86(57.6 \%)$. This study was consistent with the study conducted in the bale zone, Amhara regionand Tehran which was 76 (52.1\%) [20], 264(78.1\%) [23] And 63(50.8) [22] respectively. But, it is very low when it compares with the study conducted in Sweden which

was137 (98\%) [24] This might be due to study area, measurement criteria to say nursing process is implemented and developmental status of the country. In contrast, this study is higher than with a study conducted Debremarkos finoteSalem hospitals 46 (37.1\%) [16] and the study in selected governmental hospital of Harer and Dire Dawa $(36.6 \%)$ [17]. This variation might be due to lack of administration, monitoring and evaluation by a quality control officer in those hospitals. But in TASH, there is a strict order on implementation and a continuous monitoring and evaluation done by administrative staffs. Moreover, this hospital is a specialized referral hospital, so that it is expected to serve better standardized professional work.

In medical record review from the total 271 cards 239 includes the form necessary to register thephase of nursing process, among those only 65(24.6\%), of cards were perform all steps of nursing process in corrected way. when it compares to the study conducted in Brazil, $100 \%$ presence of available register form, this study has low availability of the charts, This difference is might be due to the differences in the study area as well as the economic developmental status of the country. Similarly the study conducted in governmental hospitals Harare, Deredawa and Tigray were $70(35 \%)$ [25], $95(26.5 \%)$ [17] of the cards includes the forms to implement nursing process among this only $95(26.5 \%)$ of the cards contain implementation of nursing process somehow this study is lower in implementation status this might be due to the sample size difference.

\subsection{Knowledge About Nursing Process}

The findings from this study identified that $38(25.2 \%)$ of respondents were has good knowledge, 50(33.1\%) were has fair knowledge and 63(41.7\%) had poor knowledge. In this study nurses who were Good knowledgeable were 10 times more likely implement nursing process than who hadpoor knowledge $[\mathrm{AOR}=9.1$ at $95 \% \mathrm{CI}(2.69,30.9)$. This study was similar with the study conducted in Bale zone hospitals, South East Ethiopia Highly knowledgeable nurses were 3 times more likely and significantly associated with implementation of nursing process than moderately and low knowledge group nurses (AOR: 3, 95\%CI: (1.302 - 8.425), P: $<0.012)(34)$, even in previous study which was conducted before six year in Addis Ababa selected hospital shows, Highly knowledgeable nurses were 38.9 times more likely and significantly associated with implementation of nursing process than low knowledge group nurses (AOR: 38.913, 95\%CI (10.3-147.006). many studies revealed that knowledge is mandatory to implement the nursing process for example, the study conducted in Nigeria on factors influencing the implementation of nursing process indicated that knowledge factor has the highest predictive value of 0.350 in the use of nursing process, then it concludes knowledge is the main factors from all the pre request criteria for nursing process implementation.

In this hospital the main gaps observed from the component of nursing process were, nursingdiagnosis, objective data collection and measuring evaluation. For instance, in diagnosis part about 56(41.8\%) state acute or chronic pain, 34\%25.5\%) state knowledge deficit and $19(14.2 \%)$ state ineffective breathing pattern. this implies there is few words of etiology used through the hospital even if there are abundant lists are present in NANDA. From the related factor $156(87.2 \%)$ of them stated disease process as a related factor even though there are different related factors present for each problem. For defining characteristics amazingly $154(96.3 \%)$ of the evidence were verbally, this result show how much the nurse working in this hospital perform the nursing diagnosis in narrow range of knowledge.

\subsection{Organizational Factors for the Implementation of Nursing Process}

Working in medical and surgical unit were 14.4 and 40 times more likely associated with implementation of nursing process than nurse working in the oncology unit. This could benurse working in medical and surgical unit had less work over load, adequate health provider(nurse to patient ratio), less flow of the patient to the ward the unit and severity or nature ofthe disease than oncology ward.

Working in the organized environment showed significant association with the implementationof the nursing process. The odds of working in organized environment were 4 times moreassociated with implementation of nursing process than compared to those who were notworking in disorganized or stress full environment $[\mathrm{AOR}=4.44,95 \% \mathrm{CI}(1.8,10.95)$. This studywas similar to a study conducted at Arbaminch general hospital in (2014) (29) [AOR8.78.(2.97-77.48) which indicated working in stress full environment was 0.23 less likely associatedwith implementation of nursing process. This could be working in the organized environmentsreinforce and stimulate activity of nurse works. In contrast if it is stress full it will increase thechance of making error and skipping some nursing activities may occur.

Other factors such as, suboptimal nurse to patient ratio (caring greater than six patients per day), rules made without consideration of staffs, inadequate resource, high work overload andunavailability of on job training are factors mainly the implementation of nursing process. Otherstudies conducted in many area states the organizational factor as predominant reason to implement the nursing process in effective way.

Additionally, patient related factors like the cooperativeness of the patients and length of stay hasassociation with implementation of nursing process. For example length of stays in a daysignificantly associated with the implementation of nursing process. Those stay in the hospital for 11-20 days and 21-30 days was 1.88(1.01, 3.53) and $2.84(1.1,7.5)$ times more likely associated with 
implementation of nursing process than staying less than ten days respectively. This result explains as the chance of the length of stays increase during admission the probability of implementing nursing process increased.

\section{Conclusion and Recommendations}

\subsection{Conclusion}

This study indicated that the status of nursing process utilization among nurse was 86 (57.6\%)however according to the medical card review, among cards contains the nursing process sheetonly $65(24.4 \%)$ of them includes all the steps of nursing process in a correct way. Significant factors associated with utilization of nursing process in this study were: level of knowledge about nursing process, working environment of the institution, the working unit orward where the nurses assigned, and the length of stay of the patients in the hospital were significant on the implementation of nursing process.

Other factors such as, sub optimal nurse to patient ratio (caring greater than six patients per day), rules made without consideration of staffs, inadequate resource, high work overload, unavailability of on job training, nurses poor attitude towards the nursing process, patient related like uncooperativeness and discharging before completing the treatment were some factors that hinder the implementation of nursing process.

\subsection{Recommendations}

It is well known that nursing process implementation is very essential to maintain nursing asprofession. The following measures should be taken to minimize some factors affectingimplementation of nursing process. For the better implementation, the principal investigatorwould like to give the following recommendations for:

\subsubsection{Nurses Scholars and Policy Maker}

(a) For nurse researchers it is better to focus to the challenges of the contemporary nursing in Ethiopia in comparison to the status of the international nursing.

(b) Produce a standardized Ethiopian nursing practice with ethical code conduct if there is any performance of actions performed below the expected criteria or qualification.

\subsubsection{Quality Control Staffs}

During monitoring and evaluation of nursing process practice, it is better to check in the standard way by following updated scientific approach this helps the nurses to work accordingly which means with the highest quality of performance. This contributes for development of the nursing profession and introduction of evidence based practice through the staff.

\subsubsection{Ministry of Education}

It should not be theory- based alone, but a period of internship should be provided with specifically in the application of the nursing process.

\subsubsection{Hospital (Administration Staffs, Finance Office, Human Resource)}

Provide opportunities like on job training or periodical training to update the knowledge of nursing process.

Provide some important charts, guidelines, text books on the wards this helps the nurses to initiate reading mood to update their knowledge. The hospital should provide the appropriate supply of instruments for nursing care.

\section{Strength and Limitation of the Study}

Strength of the Study

(a) This study used medical card review which is not included in many studies. This helps to compare the reliability of the nurses' responses to the result of the card review towards the implementation of nursing process.

(b) Data collectors are recruited from staffs out sides of the hospital this decrease biases.

\section{Limitation of the Study}

(a) The study design was cross sectional which is used to investigate findings on a single point of time. So that the factors affecting implementation of nursing process out of the study period could not be investigated.

(b) Quantitative questionnaire was prone to social desirability bias; because of every one do not want to expose once inability or unwanted attitude. The mismatch in the result between the card and questionnaire $\mathrm{s}$ was an evidence for this bias.

(c) Qualitative study design was not applied in the study so that it might not address more associated factors.

\section{Conflict of Interest and Funding}

Funding for this study was made possible through grants offered by Addis Ababa University post graduate office. The authors declare that they have no competing interests.

\section{Authors' Contributions}

TH, TBand YA, conceptualized the paper, searched literature, trained field researchers for data collection and wrote the results and discussion sections. All authors participated in data analysis, interpretation and in critical review of the manuscript, and drafted the manuscript for publication and each author read and approved the final manuscript.

\section{Acknowledgements}

We are grateful to Addis Ababa University, College of Health Sciences, School of Nursing and Midwifery, for its financial and technical support. We are also very indebted 
to extend our gratitude to Federal Ministry of Health and Tikur Anbesa Specialized Hospital for granting us permission to conduct the study. The authors are also thankful to the respondents who offered their time to participate in this study. Special thanks go to the research assistants who participated in data collectionand creditedto $\mathrm{Mr}$ Zeleke Argaw for the participation of document review process.

\section{References}

[1] FMOH, nursing care practices standards, Reference manual for nurses and health care Managers in Ethiopia. Addis Ababa, Ethiopia, 2011. Page 12-14.

[2] Yildirim B, Özkahraman S, Karabudak SS. The critical thinking teaching methods in nursing students. International Journal of Business and Social Science. 2011 Dec 1; 2(24)

[3] Taylor C, Lillis C, LeMone P. Fundamental of Nursing: The Art and Science of Nursing Care. Dimensions of Critical Care Nursing. 1990 Jan 1; 9(1):28.

[4] Huckabay LM. Clinical reasoned judgment and the nursing process. In nursing Forum2009 Apr 1 (Vol. 44, No. 2, pp. 7278). Blackwell Publishing Inc.

[5] Craven RF, Hirnle CJ. Fundamentals of nursing: Human health and function. $6^{\text {th }}$ Ed. Philadelphia: Lippincott Williams \& Wilkins, 2009. Page: 126-87.

[6] Freitas MC, Queiroz TA, Souza JA. The nursing process according to the view of nursesfrom a maternity. Revista brasileira de enfermagem. 2007 Apr; 60 (2):207-12.

[7] Momoh MA, Chukwu DO. Factors that militate against the use of nursing process: Ahospital based study. Continental Journal of Pharmaceutical Sciences. 2010; 4:6-9.

[8] CatrinBjorvell: nursing documentation in clinical practice, department of nursing, karolinska institute, Stockholm, 2002, Sweden, page 10

[9] Munro N. Evidence-based assessment: no more pride or prejudice. AACN AdvancedCritical Care. 2004 Oct 1; 15(4):501-5.

[10] Pokorski S, Moraes MA, Chiarelli R, Costanzi AP, Rabelo ER. Nursing process: Fromliterature to practice. What are we actually doing? Rev Lat Am Enfermagem 2009;17:3027.

[11] Dal Sasso GT, Barra DC, Paese F, Almeida SR, Rios GC, Marinho MM, et al. Computerized nursing process: Methodology to establish associations between clinicalassessment, diagnosis, interventions, and outcomes. Rev Esc Enferm USP 2013;47:242-9.

[12] McCaughan D, Thompson C, Cullum C, Sheldon TA, Thompson DR. Acute care nurses'perceptions of barriers to using research information in clinical decision making. Journalof Advanced Nursing. 2002; 39: 46-60.

[13] Lee TT. Nursing diagnoses: factors affecting their use in charting standardized care plans. Journal of clinical nursing. 2005 May 1; 14(5):640-7.

[14] Alfaro R, Alfaro-LeFevre R. Applying nursing diagnosis and nursing process: a step bystep guide. 2nded. Philadelphia: Lippincott; 1990. P. 2.163.

[15] Hagos F, Alemseged F, Balcha F, Berhe S, Aregay A. Application of nursing process and its affecting factors among nurses working in mekelle zone hospitals, Northern Ethiopia. Nursing research and practice. 2014 Feb 6;2014.

[16] Abebe, N., Abera, H., \& Ayana, H. The Implementation of Nursing Process and Associated Factors among Nurses Working in Debremarkos and Finoteselam Hospitals, Northwest Ethiopia. Journal of Nursing Care. 2013. Volume 3 (no. 2). Page: 149-150.

[17] Sisay. H, Nega. A \& biftu. G. Nursing process and factors affecting its utilization in governmental hospitals in harari and dire dawa regions 2015.

[18] Mulugeta. A, Rajalakashmi. M and Mulugeta. M, Assessment of Factors Affecting Implementation of Nursing Process among Nurses in Selected Governmental Hospitals, Addis Ababa, Ethiopia. J Nurs Care. 2014;3(3):2.

[19] Zerihun A. Implementation and factors affecting nursing process among nurses workingin selected government hospitals in south west Ethiopia, 2015 (doctoral dissertation, AAU).

[20] Tesfaye A. Factors Affecting Implementation of Nursing Process among Nurses In BaleZone Hospitals, South East Ethiopia (Doctoral dissertation, AAU).

[21] Herdman TH, editor. Nursing diagnoses 2012-14: Definitions and classification. John Wiley \& Sons; 2011 Nov 14.

[22] Zamanzadeh V, Valizadeh L, Tabrizi FJ, Behshid M, Lotfi M. Challenges associated withthe implementation of the nursing process: A systematic review. Iranian journal of nursing and midwifery research. $2015 \mathrm{Jul} ; 20(4): 411$.

[23] Ayalew S Implementation of Nursing Process in clinical settings: the case of three governmental hospitals in Ethiopia, 2017, BMC journal. https://doi.org/10.1186/s13104-018-3275-z

[24] Jansson I, Bahtsevani C, Pilhammar-Andersson E, Forsberg A. Factors and conditions that influence the implementation of standardized nursing care plans. The open nursing journal. 2010; 4:25.

[25] Baraki et al. Across sectional study on nursing process implementation and associated factors aong nurses working in selected hospitals of central and Northwest zones, Tigray region, Ethiopia, 2017BMC nursing (2017)16:54 DOI 101186/s129-017-0248-9. 